\title{
Citizenship, human rights, and dementia: Towards a new embodied relational ethic of sexuality
}

\author{
Pia Kontos, Alisa Grigorovich, Alexis P. Kontos, and \\ Karen-Lee Miller
}

Version Post-Print/Accepted Manuscript

Citation Kontos, P., Grigorovich, A., Kontos, A., Miller, K.L. Citizenship, (published version) human rights, and dementia: Towards a new embodied relational ethic of sexuality. Dementia: The International Journal of Social Research and Practice (Special Issue on Citizenship), Vol 15, Issue 3, 2016, doi: $10.1177 / 1471301216636258$.

Publisher's Statement The final published version of this article is available via SAGE at https://dx.doi.org/10.1177/1471301216636258.

How to cite TSpace items

Always cite the published version, so the author(s) will receive recognition through services that track citation counts, e.g. Scopus. If you need to cite the page number of the author manuscript from TSpace because you cannot access the published version, then cite the TSpace version in addition to the published version using the permanent URI (handle) found on the record page.

This article was made openly accessible by $U$ of $T$ Faculty. Please tell us how this access benefits you. Your story matters. 


\title{
Citizenship, Human Rights, and Dementia: Towards a New Embodied Relational Ethic of Sexuality
}

\author{
Author Information \\ Pia Kontos, $\mathrm{PhD}$ \\ Senior Research Scientist \\ Toronto Rehabilitation Institute-University Health Network, Toronto, Canada \\ Associate Professor \\ Dalla Lana School of Public Health, University of Toronto, Toronto, Canada \\ pia.kontos@uhn.ca
}

Alisa Grigorovich, $\mathrm{PhD}$

Senior Research Associate

Toronto Rehabilitation Institute-University Health Network, Toronto, Canada alisa.grigorovich@uhn.ca

*Alexis P. Kontos, BA, LLB, LLM

Counsel, Human Rights Law Section, Department of Justice Canada

alexiskontos@yahoo.co.uk

Karen-Lee Miller, PhD, MSW

Senior Research Associate

Toronto Rehabilitation Institute-University Health Network, Toronto, Canada

Dalla Lana School of Public Health, University of Toronto, Toronto, Canada

karenlee.miller@mail.utoronto.ca

\section{Corresponding Author}

Pia Kontos, PhD

Senior Research Scientist

Toronto Rehabilitation Institute-University Health Network, Toronto, Canada Associate Professor

Dalla Lana School of Public Health, University of Toronto, Toronto, Canada

pia.kontos@uhn.ca

*The views expressed in this article by the co-author Alexis Kontos are in his personal capacity and are not necessarily shared by the Department of Justice Canada.

\section{Funding Statement}

This work was supported by the Canadian Institutes of Health Research Operating Grant (201214, MOP-114953). 


\begin{abstract}
Sexual citizenship and sexual rights scholarship have made important contributions to broadening citizenship and more fully accommodating rights related to sexuality. However, this scholarship has concentrated primarily on the sexuality and intimacy-related needs of younger people and those who are not cognitively impaired. Consequently, it has inadvertently served to marginalize persons living with dementia who reside in long-term residential care settings. We argue that supporting sexual rights for persons with dementia requires a particular human rights ontology for citizenship - one that recognizes that corporeality is a fundamental source of selfexpression, interdependence, and reciprocal engagement. This is an ontology that underpins our model of relational citizenship and that grounds our articulation of an ethic of embodied relational sexuality. In our view, this ethic offers important direction for the development of policy, legislation, and clinical guidelines to support sexual rights for persons with dementia in long-term residential care.
\end{abstract}

Key words: embodied selfhood, relationality, sexual citizenship, sexual rights, ethics, long-term care 


\section{Introduction}

Affection and intimacy are considered to be universal needs that transcend age, cognitive decline, and disability (Bauer et al., 2013; Casta-Kaufteil, 2003; Gott \& Hinchliff, 2003; Hill, 2014; Ni Lochlainn \& Kenny; Shildrick, 2007). There also is a general consensus on the beneficial effects of intimacy and sexuality for older people, which include pleasure and intimacy, decreased pain sensitivity, increased relaxation, and lower levels of depression (Hajjar \& Kamel, 2004; Ni Lochlainn \& Kenny; Syme, 2014). However, there is a long history of sociocultural stereotyping of disabled and aged sexuality as being heteronormative, inhibited, or totally inactive (De Beauvoir, 1996; Gott, 2004; Shildrick, 2007; Ward, Pugh, \& Price, 2010). These attitudes have effectively prevented proper consideration of the sexual needs of older adults and persons with disabilities as they relate to policy, legislation, and clinical guidelines. This is most apparent in long-term residential care settings where multiple barriers to sexual expression exist (e.g. lack of private space and constant surveillance) and where health care practitioners are often ill-prepared to address the sexual needs of residents with dementia (Frankowski \& Clark, 2009; Hajjar \& Kamel, 2004; Mahieu \& Gastmans, 2012; Roach, 2004; Tzeng, Lin, Shyr, \& Wen, 2009; Villar, Celdrán, Fabà, \& Serrat, 2014; Ward, Vass, Aggarwal, Garfield, \& Cybyk, 2005). How to support individuals' sexual needs through changes in policy and legislation has received theoretical attention from scholarship on sexual citizenship and sexual rights where the focus has been the removal of barriers to autonomous sexual expression (Dixon-Mueller, Germain, Fredrick, \& Bourne, 2009; Plummer, 2003; Richardson, 1998, 2000b). Yet this literature leaves unaddressed the support of individuals who are deemed incapable of decision-making, particularly in the case of dementia (Casta-Kaufteil, 2003; Kulick \& Rydstrom, 2015; Shildrick, 2007). The autonomy-focused discussion in this scholarship arguably gives rise to an absolutization of rationality and cognition, both of which are impaired 
with dementia (Everett, 2007; Hughes, Beatty, \& Shippen, 2014; Mahieu, Anckaert, \& Gastmans, 2014b; Rushbrooke, Murray, \& Townsend, 2014). Thus, in order to better support the right to sexual expression in dementia, what is needed is a model of citizenship with a human rights ontology that more broadly recognizes the agential status of embodied self-expression. This ontology underpins a model of relational citizenship we have advanced elsewhere (Kontos, Miller, \& Kontos, Under review; Miller \& Kontos, Forthcoming). However we have yet to articulate this ontology specifically towards an ethic of embodied relational sexuality that can be used to guide the development of policy, legislation, and clinical guidelines, which is our purpose here.

We begin by tracing and critiquing scholarship on sexual citizenship and sexual rights, highlighting their limitations in supporting the sexual expression of persons with dementia in long-term residential care. To redress these limitations, we explicate our relational model of citizenship (Kontos et al., Under review; Miller \& Kontos, Forthcoming) and its foundationalist human rights ontology. Finally, contra biomedical ethics, we advance ethical principles premised on this relational model, with our conclusions focusing on the multiscalar implications of this ethic.

\section{Sexual Citizenship and Sexual Rights}

Sexual citizenship has many features in common with other claims to citizenship. It is about enfranchisement, about belonging, about equity and justice, and about rights balanced by responsibilities. It emerged as a distinct sub-field of citizenship out of concern for the need to broaden the conceptualization of citizenship to accommodate not only class and race, but also gender and sexuality (Bell \& Binnie, 2000; Cossman, 2007; Lister, 2007; Phelan, 2010; 
Plummer, 2001; Richardson, 1998, 2000a, 2000b; Weeks, 1998). Distinct challenges posed by this sub-field include the identification that citizenship is heteronormatively constructed and that sexual minorities and other marginalized social groups are excluded from citizenship entitlements. Scholars have used the concept of sexual citizenship to articulate and support rights claims (economic, legal, and social) based on sexual conduct, identity, and relationships (Richardson, 1998, 2000b).

At the same time as sexual citizenship, an alternative stream of sexual rights discourse emerged with a different focus (Lottes, 2013; Richardson, 2015). This discourse draws on human rights principles (as articulated in international human rights declarations and treaties) to argue for the need to globally support access to sexual and reproductive health services (e.g. abortion), protect individuals from sexual and gender-based violence, and challenge criminalization of certain sexual acts (Cottingham et al., 2010; Dixon-Mueller et al., 2009; Lottes, 2013). In particular, it frames its arguments for actualizing sexual rights claims not based on individuals' formal membership in a nation-state (i.e. citizenship is a legal status based on nationality that is conferred by a state at birth or through naturalization), but on the basis of being human (Cottingham et al., 2010; Lottes, 2013; Tiefer, 2002). Human rights are premised on fundamental principles such as universality, equality and non-discrimination, security, and dignity (Boersema, 2011; United Nations, 1948; World Health Organization \& United Nations Office of the High Comissioner for Human Rights, 2008; Wronka, 2007). These rights are considered to be interdependent, indivisible, and inalienable, which implies that each human right is dependent upon the realization of other human rights and that such rights are "natural" by virtue of being fundamentally human (Carozza, 2003; Kiwan, 2005; Somers \& Roberts, 2008). 
The turn to human rights principles in scholarship on sexual rights is consistent with some citizenship scholars who have argued for the need to reconceptualize citizenship with an ontology of human rights (Somers \& Roberts, 2008; Turner, 2006, 2009). For example, Turner $(1993,2006)$ argues that this ontology can be based on universal bodily frailty in a global system. The appeal of using human rights to furnish the ontological foundation for citizenship is that citizenship claims have purchase only in the context of a particular socio-political body. Human rights, by contrast, transcend political and/or social boundaries by virtue of their universality. These authors contend that citizenship and human rights are nonetheless compatible and that citizenship allows for the local realization of human rights through socio-political institutions and organizational practices at the local level of citizenship (Carozza, 2003; Isin \& Turner, 2007; Nussbaum, 1997; Somers, 2008; Somers \& Roberts, 2008; Turner, 1993, 2009). Human rights are also "naturally social” as, according to Carozza (2003), the realization of one's inherent and inalienable worth can only be achieved in association with others.

Collectively, the sub-fields of sexual citizenship and sexual rights have harnessed feminist, women's health, and lesbian, gay, bisexual, trans, queer, and intersex (LGBTQI) activists' and scholars' claims to rights related to safety, bodily control, sexual self-determination (e.g. the right to freely choose sexual partners) and the public recognition of diverse sexual identities. However, though pivotal in broadening the concept of citizenship and more fully accommodating rights related to sexuality, these claims have been concentrated primarily on the sexuality and intimacy-related needs of younger people (e.g. ensuring access to reproductive services and access to marriage). Further, the focus on the sexual citizen as a "choosing subject," capable of self-definition, choice, and autonomy, has perhaps inadvertently served to marginalize individuals for whom those dimensions of agency (e.g. cognitive capacity to make a 
choice) are considered impaired, such as in the case of persons living with dementia (Bacchi \& Beasley, 2002; Richardson, 2015; Shildrick, 2007). This falls short of capturing how corporeality - including movements, gestures, senses, and socio-cultural dispositions of the body - is a fundamental source of the capacity for self-expression, interdependence, and reciprocal engagement, which defines human agency (Kontos, 2003, 2014). The broadening of agency to include corporeality as a fundamental source of human agency (Kontos, 2006b) is critical to better support sexual rights of persons living with dementia. Thus, what is needed is a human rights ontology for citizenship that more broadly recognizes the agential status of embodied selfexpression. This ontology is reflected in our model of relational citizenship; a model that incorporates the central tenets of relationality and embodied selfhood theory (Miller \& Kontos, Forthcoming).

\section{Relational citizenship model}

The first tenet of the model, embodied selfhood (Kontos, 2004a, 2005, 2006a, 2012a), has emerged from a subfield of dementia studies that puts the body and embodied practices at the centre of explorations of how dementia is represented and/or experienced. A critique of self/body duality is an implicit starting point for scholars who have sought to reframe and reclaim the self in Alzheimer's disease (Hubbard, Tester, \& Downs, 2003; Sabat, 2006; Sabat \& Harré, 1992). This has been accomplished via historical analyses (Katz, 2012), as well as philosophical (Hughes, 2001; Kontos, 2004b; Matthews, 2006; Millett, 2011) and empirical explorations (Kontos, 2004a, 2012b; Twigg, 2010), which have deconstructed the Enlightenment's "cerebral subject" as based on the coupling of memory, mind, and selfhood (Katz, 2012). This work forms an important theoretical foundation for problematizing the focus on pathology, autonomy, and 
management that is driving current conceptions of how to “deal ethically with residents' sexual expression” (Mahieu, Anckaert, \& Gastmans, 2014a, p. 8).

Embodied selfhood takes its theoretical bearings from Merleau-Ponty's reconceptualization of perception (1962) and Bourdieu's concept of habitus (1977, 1990). This advances a notion of selfhood that considers both the pre-reflective intentionality of the body and its natural (pre-social) engagement with the world (the body's power of natural expression), and the ongoing socio-cultural relationship between the pre-reflective body and the world (history, culture, power, and discourse). Together, these theoretical bearings capture the pre-reflective capacity of the body to seize upon and transform the perceptible into something meaningful. The body here is intentional in its capacity to perceive and experience (Kontos, 2006b). This importantly challenges assumptions of loss of agency with dementia, by treating the body as itself having creative and intentional capacity. Thus, even in the face of cognitive impairment, agency persists.

Relationality is the second core tenet of our relational citizenship model, which builds on relationship-centred care (Adams \& Gardiner, 2005; Nolan, Ryan, Enderby, \& Reid, 2002), a paradigm that seeks to redress the focus on persons with dementia to the exclusion of those who informally or formally provide their care (Ryan et al. 2008). Relationship-centred care aims to more fully capture "the interdependencies and reciprocities that underpin caring relationships" (Nolan et al., 2002, p. 203). However, since relationship-centred care has not engaged critical gerontology's emerging theoretical subfield of embodiment and dementia, we draw on embodied selfhood to capture the importance of primordial and socio-cultural dispositions of the body as agential sources of self-expression, which are critical to broadening understanding of relationality. Relationality is understood here not as a function of cognitive agency but rather as 
embodied, with embodied selfhood as a primary agential source of interactive and communicative practices for persons living with dementia (Kontos, 2012b). The significance of embodied selfhood for relationality has been explored empirically and theoretically, demonstrating that coherence, as well as distinctiveness, can be discerned in the interactive practices of persons with dementia (Kontos, 2006a, 2012a, 2012b).

Here we wish to argue that embodied self-expression must be recognized as fundamental to the human condition and thus supported in and through a matrix of human rights (e.g. rights to privacy, freedom of expression, liberty, health, and human dignity). The proposed model of relational citizenship is particularly pertinent for supporting the sexual rights of individuals with dementia because it recognizes sexuality as integral to embodied self-expression. Further, with our proposed ontology of human rights underpinning our model of citizenship, sexual rights would be recognized and supported through institutional policies, structures and practices. In so doing, relational citizenship more inclusively grants sexual rights entitlements to persons living with dementia who have long been marginalized and silenced.

\section{Ethical frameworks to support sexual rights}

\section{Biomedical}

Given the significant benefits of sexual expression, there has been a call for the development of guidelines and policies to address sexuality in long-term care settings. To this end, reference is typically made to the four moral principles approach of biomedical ethics (Beauchamp \& Childress, 2009) to guide the conduct of health care practitioners in clinical settings: respect for autonomy; beneficence; non-maleficence; and justice (Everett, 2007; Kamel \& Hajjar, 2004; Mahieu et al., 2014a, 2014b; Mahieu \& Gastmans, 2012). The principle of 
respect for autonomy is founded upon the aspirational ideal of the autonomous agent who acts in accordance with a freely self-chosen and informed plan. Autonomy is mainly described as the right to self-determination. Within clinical practice, the principle of respect for autonomy is reflected in the ethical concept of informed consent (Casta-Kaufteil, 2003; Mahieu \& Gastmans, 2012). Consent measures have been designed to enable the autonomous choice of patients regarding medical intervention. Respect for autonomy, however, is not confined to the concept of informed consent alone. It also extends to specific autonomy-related rights, such as the right to privacy (Mahieu \& Gastmans, 2012). When it comes to sexuality within a long-term care settings, the general right to privacy can also be subdivided into three different categories: physical privacy; privacy of information; and privacy of association (Mahieu \& Gastmans, 2012).

The principle of beneficence is the obligation to do and promote good. Non-maleficence refers to the obligations to protect fellow human beings from evil or harm. Within the context of sexuality, this means that the duty to protect especially relates to the risk of unreasonable harm associated with the sexual behavior concerned. These principles also denote the obligation not to inflict harm. The permissibility of intervening in the resident's sexual behavior mainly depends on the involvement of harm to self, or harm or offense to others. When harm to the self is an issue there are two concerns: the capacity to consent to sexual activity and the reasonableness of the associated risks (Everett, 2007; Mahieu \& Gastmans, 2012). Finally, the principle of justice refers to the obligation to ensure equal treatment and prevent violence and discrimination (Mahieu \& Gastmans, 2012; Ward et al., 2005).

While these principles offer a framework for sexual ethics for guiding practitioners' practices in long-term care settings, they have not been received without critique (Everett, 2007; 
Mahieu \& Gastmans, 2012). For example, the principle of autonomy is premised on "all or nothing global competence" (Mahieu \& Gastmans, 2012, p. 349). Since dementia is marked by a progressive deterioration in cognition that affects reasoning capacity, persons with dementia fall short of the ideal of the autonomous agent that grounds the principle of respect for autonomy (Kamel \& Hajjar, 2004). The current focus on informed consent not only runs the risk of leading us to an autonomy-focused discussion which gives rise to an absolutization of rationality and cognition, it also reinforces a divide between those who are living with dementia and others. Further, it sets the bar for undue interference significantly high, with the application of this principle erring on the side of a duty to intervene over freedom of sexual expression (Everett, 2007).

Concerns have also been expressed about supporting autonomy-related rights in relation to privacy (Bauer et al., 2013; Parker, 2007; Tzeng et al., 2009; Villar et al., 2014; Ward et al., 2005), specifically that the physical environment of a long-term care home is not designed with the privacy of residents in mind (e.g. open concept design, "open door" or "no locked door" policies, and high-backed chairs vs. sofas). Also, few nursing homes have policies to protect residents' sexual privacy (Bauer, 1999; Frankowski \& Clark, 2009; Hill, 2014), such as allowing for the display and use of sexually themed materials in private rooms or the establishment of private spaces for sexual activity with privacy curtains or separate rooms, for example (Hajjar \& Kamel, 2004). Information about residents' sexuality is also routinely shared with family members (e.g. spouses and children) without considering this to be a violation of residents' right to privacy and autonomy (Bauer et al., 2013; Bauer et al., 2014; Hill, 2014; Mahieu et al., 2014b). One corrective to this practice has been the suggestion that sharing should be based on 
the principle of "need to know" and that spouses (as sexual partners) may have a greater need to know than children (Mahieu et al., 2014a).

These critiques have identified significant issues with how biomedical ethics have been applied to the management of residents' sexual expression (Mahieu et al., 2014b). However, they leave unaddressed the social construction of sexuality in dementia as a problem to be managed and treated (Parker, 2007). Sexuality has been the target of medical intervention through the construction of the classification of "inappropriate sexual behaviour" (ISB). ISB is a discourse that views all sexual expression in dementia through a lens of pathology and thus deems it subject to biomedical intervention (Cipriani, Ulivi, Danti, Lucetti, \& Nuti, 2015; Guay, 2008). For example, affection or courtship directed towards a care provider or another resident is assumed to be misdirected and thus pathological, or a subtype of ISB (Cipriani et al., 2015).

More recently, some scholars have argued that ISB should be confined only to disinhibited sexual behaviour or hypersexuality (understood to be beyond the control of the individual), so as not to pathologize normal sexual longings and expressions (see, for example, Guay, 2008). Further, context should be accounted for when determining whether an expression is ISB, highlighting the importance of immediate factors such as a non-sexual causes of the expression (e.g. forgetting to get dressed before entering a public space) and more distal factors such as "iatrogenic loneliness" (Miles \& Parker, 1999) induced by staff attitudes and organizational structures that fail to accommodate any form of intimacy within the institutional setting.

While these critical analyses importantly challenge the construction of ISB, they nonetheless fail to address what constitutes "normal" in the context of dementia (Mahieu et al., 2014a). The net of pathology is cast so widely in dementia (Dupuis, Wiersma, \& Loiselle, 2012; 
Mitchell, Dupuis, \& Kontos, 2013; Whitehouse, 2008) - indeed the prevalent assumption is that with advancing dementia selfhood is extinguished (Davis, 2004) - that despite laudable efforts to allow for normal sexual expressions, the focus remains on managing ISB or supporting the sexuality of people without dementia. We thus argue for the need to draw on ethical principles premised on a different ontology than that underpinning biomedical discourse and biomedical ethics, as that ontology is premised on the 'loss of selfhood' paradigm (Kontos, 2004b; Mitchell et al., 2013). Instead, we argue for a human rights ontology that valorizes embodied selfexpression and relationality.

\section{Embodied relationality}

Our embodied relational framework for ethics is premised on the same foundational human rights ontology as our relational model of citizenship (Kontos et al., Under review; Miller \& Kontos, Forthcoming). As discussed above, the core tenets of this model include embodied selfhood and relationality, which foreground the body's pre-reflective capacity to inform and express distinctiveness and relationality. As such, embodied relationality is a framework that upholds sexuality as fundamental to embodied self-expression; sexual expression is valued for its own sake rather than for instrumental purposes (e.g. reproduction) and is a universal human need regardless of the presence or degree of cognitive impairment (Appel, 2010; Bauer, 1999; Bauer et al., 2013; Dixon-Mueller et al., 2009; Lottes, 2013; Tepper, 2000). Within this framework, persons with dementia have the "right to experience a pleasurable sexuality, which is essential in and of itself" (HERA quoted in Dixon-Mueller et al., 2009, p. 112). Of course, supporting the right to sexual expression should not be taken to imply that protection from unwanted contact or sexual harm is unnecessary, particularly given that both occur in long-term residential care settings (Malmedal, Iversen, \& Kilvik, 2015). However, freedom of sexual expression, like all 
other forms of freedom, should only be restricted in as much as is necessary to protect the health and safety of the individuals involved (Appel, 2010; Dixon-Mueller et al., 2009).

Our proposed framework importantly broadens the exclusive goal of sexual ethics based on the biomedical framework from the duty only to protect individuals from harm, to the duty also to uphold and support their sexual rights in long-term care settings. Supporting sexual rights in this context becomes more than recognizing an "identity-based claim" to sexual expression (Richardson, 2000b), as this often results only in the removal of barriers to autonomous sexual expression (Appel, 2010). Instead, with this framework, the support of sexual rights encompasses a broader focus on how to mobilize socio-cultural and political structures to nurture and facilitate sexuality and individuals' needs for sexual expression and intimacy (Shakespeare, 2003). This shift from recognition to support is a defining feature of a right since the enjoyment of rights always depends on social structures through which power, material resources, and meanings are created and circulated (Somers, 2008; Somers \& Roberts, 2008; Turner, 2006).

The embodied relational ethic encompasses both the removal of barriers and the implementation of facilitators using a multiscalar approach to cultivate residents' sexual expression. The sexuality of persons living with dementia, as with people with disabilities more generally, are not part of the cultural imaginary, which is characterized as "those ready-made images and symbols through which we make sense of social bodies, and which determine, in part, their value, their status, and what will be deemed their appropriate treatment" (Gatens, 1996, p. viii). The call for supporting sexual expression of persons with dementia thus must address at the broadest level the social denigration of dementia and sexuality that is deeply entrenched in western culture and in long-term care policies and practices (Mahieu et al., 2014a; Shildrick, 2007; Ward et al., 2005). 
Supporting sexual expression of persons with dementia will require introducing public health and policy initiatives to raise awareness and to counteract deeply seated perceptions of aged sexuality and dementia that foster discriminatory and marginalizing practices (Heath, 2011; Ward et al., 2010). These initiatives would include redressing prevalent heterosexist and heteronormative assumptions in order to support sexual and gender diversity in long-term care, and to challenge homo-/lesbo-/bi-/transphobia (Grigorovich, 2015a, 2015b; Kontos et al., Under review; Ward et al., 2010; Willis et al., 2013). They would also ensure that care staff have a better understanding of diverse residents' experiences and needs regarding intimacy and sexuality, and how these can be supported. Sexuality has yet to be incorporated into pedagogical strategies to achieve such culture change in long-term care settings. Thus, educational initiatives regarding sexuality and embodied relationality should be integral to the training of all long-term care staff and, as Bauer et al. (2014) have suggested, should also be discussed with family care partners who are largely neglected in initiatives to support residents' sexuality. Finally, residents should also receive access to information about diverse sexual and gender expression and their sexual rights.

Organizational practices are also implicated in this ethic. In the context of individual long-term care homes, administrators should identify and correct current oppressive practices (e.g. prohibition of co-habitation, prohibition against use of sexual materials, and staff not knocking before entering residents' private rooms). Additionally administrators and health care practitioners should initiate discussion with family members and residents regarding residents' rights to sexual expression, as it is questionable in many cases whether residents and families are aware of these rights (Bauer, Nay, \& McAuliffe, 2009; Bentrott \& Margrett, 2011). It also entails the development of clinical and occupational health and safety guidelines. It is recommended 
that such development be a joint undertaking by formal and informal care partners and persons living with dementia (Vancouver Coastal Health Authority, 2009; Villar et al., 2014).

Fostering an organizational culture that supports sexual expression requires tackling injustice and inequality not only by implementing anti-oppressive policies and practices (Hafford-Letchfield, 2008; Willis et al., 2013), but also by supporting sexual rights, which, in this context, requires facilitation of residents' sexuality through the provision of opportunities for sexual activities and sexual expression (Vancouver Coastal Health Authority, 2009). For example, it has been suggested that a holistic approach to nursing care should include nurses providing patients support with "the continuum of facilitated sex" (Earle, 2001, p. 436). This could entail providing assistance with a wide number of activities, including the procurement of erotic aids (e.g. pornography), sexual intercourse, and masturbation.

Examples of facilitation that are already occurring in some long-term care homes include: hosting social events and romantic outings for residents (Kamel \& Hajjar, 2004), such as the U.K. home that hosts weekly "bar nights" involving the creation of a bar environment in the main area of a long-term care home with drinks (Archibald, 2002); the institution of "sexual advisors" such as in the case of Denmark where social workers certified in sexuality and disability provide residents with sexual education, counselling and facilitation (Kulick \& Rydstrom, 2015); and providing assistance for residents to procure sex workers (Gardner, 2013; Obermueller, 2011). Finally, some have suggested that new roles are required in order to support sexual pleasure such as the use of volunteers from charitable non-profit organizations (Di Nucci, 2011) and the purchase of sex work (covered publically by the state) even in jurisdictions where it is legally prohibited (Appel, 2010). 
Nonetheless, there is a complex array of ethical, legal, personal, and professional considerations involved in the development of an organizational culture that supports sexual expression for persons with dementia living in long term care settings. Not only is there the need to balance residents' rights to sexual expression with protection from undue risk, particularly with regard to sexual harm, but we must also consider the rights of care providers, for whom facilitation of residents' sexual expression may constitute a moral compromise and/or a compromise of their own sexual rights (Archibald, 2002, 2003; Earle, 2001). Engaging formal and informal carers and persons with dementia will be critical for addressing this complexity in the evolution of clinical and occupational health and safety guidelines (Villar et al., 2014). However, to date, there has been scant consideration of the perspectives of formal and informal care providers, and even less for residents of long term care with dementia (Roelofs, Luijkx, \& Embregts, 2015), which is crucial for the design of best practices and policies in long term care.

\section{Conclusion}

The turn to human rights in citizenship discourse is an important development given concerns that citizenship alone cannot ensure the necessary protection, recognition, and support of diverse members of society with different needs, capacities, and circumstances. However, as we have argued, to support sexual rights for persons with dementia, a particular human rights ontology is needed - one that recognizes the agential status of embodied self-expression. This is consistent with the call for more critical engagement by citizenship scholars with embodiment discourse (Beasley \& Bacchi, 2000; Miller \& Kontos, Forthcoming). The ontology of our relational model of citizenship is novel in that it recognizes corporeality and relationality as fundamental for self-expression, interdependence, and reciprocal engagement. Foregrounding 
the body's pre-reflective capacity to inform and express distinctiveness and relationality heralds a more inclusive approach to the recognition and facilitation of sexual expression in dementia.

Based on our model of citizenship, our ethic of embodied relational sexuality can be used to guide the development of policy, legislation, and clinical guidelines that support sexual rights and thereby advance relational citizenship in practice. For example, long-term care homes that embrace this ethic would provide education and training and support residents' sexuality by creating opportunities for their sexual expression, including forming sexual and intimate relationships with other residents and accessing sexually-themed materials and/or sexual services. This might alleviate formal care providers' sense of discomfort when presented with sexual expressions by residents (Archibald, 2003; Villar et al., 2014).

Our hope is that relational citizenship and the ethic of embodied relational sexuality will be taken up by other scholars equally committed to ensuring that persons with dementia are entitled to experience freedom from discrimination and have equal opportunities to participate in life - including the pursuit of intimate sexual activities and relations - to the fullest extent possible. 


\section{References}

Adams, T., \& Gardiner, P. (2005). Communication and interaction within dementia care triads: Developing a theory for relationship-centred care. Dementia, 4(2), 185-205.

Appel, J. M. (2010). Sex rights for the disabled? Journal of Medical Ethics, 36(3), 152-154. doi: 10.1136/jme.2009.033183

Archibald, C. (2002). Sexuality and dementia in residential care--whose responsibility? Sexual and Relationship Therapy, 17(3), 301-309. doi: 10.1080/14681990220149103

Archibald, C. (2003). Sexuality and dementia: The role dementia plays when sexual expression becomes a component of residential care work. Alzheimer's Care Today, 4(2), 137-148.

Bacchi, C. L., \& Beasley, C. (2002). Citizen bodies: Is embodied citizenship a contradiction in terms? Critical Social Policy, 22(2), 324-352.

Bauer, M. (1999). Their only privacy is between their sheets: Privacy and the sexuality of elderly nursing home residents. Journal of Gerontological Nursing, 25(8), 37-41.

Bauer, M., Fetherstonhaugh, D., Tarzia, L., Nay, R., Wellman, D., \& Beattie, E. (2013). 'I always look under the bed for a man'. Needs and barriers to the expression of sexuality in residential aged care: The views of residents with and without dementia. Psychology \& Sexuality, 4(3), 296-309. doi: 10.1080/19419899.2012.713869

Bauer, M., Nay, R., \& McAuliffe, L. (2009). Catering to love, sex and intimacy in residential aged care: What information is provided to consumers? Sexuality and Disability, 27(1), 3-9. doi: 10.1007/s11195-008-9106-8

Bauer, M., Nay, R., Tarzia, L., Fetherstonhaugh, D., Wellman, D., \& Beattie, E. (2014). 'We need to know what's going on': Views of family members toward the sexual expression of people with dementia in residential aged care. Dementia, 13(5), 571-585. doi: $10.1177 / 1471301213479785$

Beasley, C., \& Bacchi, C. (2000). Citizen bodies: Embodying citizens - a feminist analysis. International Feminist Journal of Politics, 2(3), 337-358. doi: 10.1080/14616740050201931

Beauchamp, T. L., \& Childress, J. F. (2009). The principles of biomedical ethics. New York, NY: Oxford University Press.

Bell, D., \& Binnie, J. (2000). The sexual citizen: Queer politics and beyond. Cambridge, UK: Polity.

Bentrott, M. D., \& Margrett, J. A. (2011). Taking a person-centered approach to understanding sexual expression among long-term care residents: Theoretical perspectives and research challenges. Ageing International, 36(3), 401-417. doi: 10.1007/s12126-011-9110-7

Boersema, D. (2011). Philosophy of human rights. Boulder, CO: Westview Press.

Bourdieu, P. (1977). Outline of a theory of practice (R. Nice, Trans.). Cambridge, UK: Cambridge University Press.

Bourdieu, P. (1990). The logic of practice (R. Nice, Trans.). Cambridge, UK: Polity Press.

Carozza, P. G. (2003). Subsidiarity as a structural principle of international human rights law. The American Journal of International Law, 97(38), 38-79.

Casta-Kaufteil, A. (2003). Old \& the restless: Mediating rights to intimacy for nursing home residents with cognitive impairments. Journal of Medicine \& the Law, 8, 69-86.

Cipriani, G., Ulivi, M., Danti, S., Lucetti, C., \& Nuti, A. (2015). Sexual disinhibition and dementia. Psychogeriatrics, 1-9. doi: 10.1111/psyg.12143 
Cossman, B. (2007). Sexual citizens: The legal and cultural regulation of sex and belonging. Stanford, CA: Stanford University Press.

Cottingham, J., Kismodi, E., Martin Hilber, A., Lincetto, O., Stahlhofer, M., \& Gruskin, S. (2010). Using human rights for sexual and reproductive health: Improving legal and regulatory frameworks. Bulletin of the World Health Organization, 88, 551-555. doi: 10.2471/BLT.09.063412

Davis, D. (2004). Dementia: Sociological and philosophical constructions. Social Science and Medicine, 58(2), 369-378.

De Beauvoir, S. (1996). The coming of age (P. O'Brian, Trans.). New York, NY: WW Norton \& Company.

Di Nucci, E. (2011). Sexual rights and disability. Journal of Medical Ethics, 37(3), 158-161.

Dixon-Mueller, R., Germain, A., Fredrick, B., \& Bourne, K. (2009). Towards a sexual ethics of rights and responsibilities. Reproductive Health Matters, 17(33), 111-119. doi: $10.2307 / 40647616$

Dupuis, S., Wiersma, E., \& Loiselle, L. (2012). Pathologizing behavior: Meanings of behaviors in dementia care. Journal of Aging Studies, 26(2), 162-173.

Earle, S. (2001). Disability, facilitated sex and the role of the nurse. Journal of Advanced Nursing, 36(3), 433-440. doi: 10.1046/j.1365-2648.2001.01991.x

Everett, B. (2007). Ethically managing sexual activity in long-term care. Sexuality and Disability, 25(1), 21-27. doi: 10.1007/s11195-006-9027-3

Frankowski, A. C., \& Clark, L. J. (2009). Sexuality and intimacy in assisted living: Residents' perspectives and experiences. Sexuality Research \& Social policy : Journal of NSRC, 6(4), 25-37. doi: 10.1525/srsp.2009.6.4.25

Gardner, B. (2013). Care home call girls: Staff invite prostitutes for residents, The Argus. Retrieved from http://www.theargus.co.uk/news/10189344.print/

Gatens, M. (1996). Imaginary bodies: Ethics, power, and corporeality. London, UK: Routledge.

Gott, M. (2004). Sexuality, sexual health and ageing. Maidenhead, UK: McGraw-Hill Education (UK).

Gott, M., \& Hinchliff, S. (2003). How important is sex in later life? The views of older people. Social Science \& Medicine, 56(8), 1617-1628.

Grigorovich, A. (2015a). The meaning of quality of care in home care settings: Older lesbian and bisexual women's perspectives. Scandinavian Journal of Caring Sciences, 1-9. doi: $10.1111 / \mathrm{scs} .12228$

Grigorovich, A. (2015b). Negotiating sexuality in home care settings: Older lesbians and bisexual women's experiences. Culture, Health \& Sexuality, 17(8), 947-961. doi: 10.1080/13691058.2015.1011237

Guay, D. R. P. (2008). Inappropriate sexual behaviors in cognitively impaired older individuals. The American journal of geriatric pharmacotherapy, 6, 269-288.

Hafford-Letchfield, T. (2008). What's love got to do with it? Developing supportive practices for the expression of sexuality, sexual identity and the intimacy needs of older people. Journal of Care Services Management, 2(4), 389-405.

Hajjar, R. R., \& Kamel, H. K. (2004). Sexuality in the nursing home, part 1: Attitudes and barriers to sexual expression. Journal of the American Medical Directors Association, 5(2), S43-S47. doi: 10.1016/S1525-8610(04)70092-4

Heath, H. (2011). Older people in care homes: Sex, sexuality and intimate relationships. London, UK. 
Hill, E. (2014). We'll always have shady pines: Surrogate decision-making tools for preserving sexual autonomy in elderly nursing home residents. William \& Mary Journal of Women \& the Law, 20.

Hubbard, G., Tester, S., \& Downs, M. G. (2003). Meaningful social interactions between older people in institutional care settings. Ageing \& Society, 23(1), 99-114.

Hughes, J. C. (2001). Views of the person with dementia. Journal of Medical Ethics, 27, 86-91.

Hughes, J. C., Beatty, A., \& Shippen, J. (2014). Sexuality in dementia. In C. Foster, J. Herring \& I. Doron (Eds.), The law and ethics of dementia (pp. 227-238). Oxford, UK: Hart Publishing.

Isin, E. F., \& Turner, B. S. (2007). Investigating citizenship: An agenda for citizenship studies. Citizenship Studies, 11(1), 5-17.

Kamel, H. K., \& Hajjar, R. R. (2004). Sexuality in the nursing home, part 2: Managing abnormal behavior-legal and ethical issues. Journal of the American Medical Directors Association, 5(2), S49-S52. doi: 10.1016/S1525-8610(04)70094-8

Katz, S. (2012). Embodied memory: Ageing, neuroculture, and the genealogy of mind. Occasion: Interdisciplinary Studies in the Humanities, 4(May 31). http://occasion.stanford.edu/node/97

Kiwan, D. (2005). Human rights and citizenship: An unjustifiable conflation? Journal of Philosophy of Education, 39(1), 37-50. doi: 10.1111/j.0309-8249.2005.00418.x

Kontos, P. (2003). 'The painterly hand': Embodied consciousness and alzheimer's disease. Journal of Aging Studies, 17, 151-170.

Kontos, P. (2004a). Embodied selfhood: Redefining agency in alzheimer's disease. In E. Tulle (Ed.), Old age and agency (pp. 105-121). Hauppauge, NY: Nova Science Publishers.

Kontos, P. (2004b). Ethnographic reflections on selfhood, embodiment and alzheimer's disease. Ageing \& Society, 24(6), 829-849.

Kontos, P. (2005). Embodied selfhood in alzheimer's disease: Rethinking person-centred care. Dementia: The International Journal of Social Research and Practice, 4(4), 553-570.

Kontos, P. (2006a). Embodied selfhood: An ethnographic exploration of alzheimer's disease. In L. Cohen \& A. Leibing (Eds.), Thinking about dementia: Culture, loss, and the anthropology of senility (pp. 195-217). New Brunswick, N.J: Rutgers University Press.

Kontos, P. (2006b). Habitus: An incomplete account of human agency. American Journal of Semiotics, 22, 67-83.

Kontos, P. (2012a). Alzheimer expressions or expressions despite alzheimer's?: Philosophical reflections on selfhood and embodiment. Occasion: Interdisciplinary Studies in the Humanities, 4(May 31), 1-12. http://arcade.stanford.edu/sites/default/files/article_pdfs/OCCASION_v04_Kontos_0531 12_0.pdf.

Kontos, P. (2012b). Rethinking sociability in long-term care: An embodied dimension of selfhood. Dementia: The International Journal of Social Research and Practice, 11(3), 329-346.

Kontos, P. (2014). Musical embodiment, selfhood, and dementia. In L. C. Hydén, J. Brockmeier \& H. Lindemann (Eds.), Beyond loss (pp. 107-119). New York: Oxford University Press.

Kontos, P., Miller, K. L., \& Kontos, A. (Under review). Embodied selfhood and reciprocity: Towards a relational model of citizenship. Sociology of Health \& Illness. 
Kulick, D., \& Rydstrom, J. (2015). Lonliness and its opposite: Sex, disability, and the ethics of engagement. Durham, NC: Duke University Press.

Lister, R. (2007). Inclusive citizenship: Realizing the potential. Citizenship Studies, 11(1), 49-61. doi: 10.1080/13621020601099856

Lottes, I. L. (2013). Sexual rights: Meanings, controversies, and sexual health promotion. Journal of Sex Research, 50(3-4), 367-391. doi: 10.1080/00224499.2013.764380

Mahieu, L., Anckaert, L., \& Gastmans, C. (2014a). Eternal sunshine of the spotless mind? An anthropological-ethical framework for understanding and dealing with sexuality in dementia care. Medicine, Health Care and Philosophy, 17(3), 377-387.

Mahieu, L., Anckaert, L., \& Gastmans, C. (2014b). Intimacy and sexuality in institutionalized dementia care: Clinical-ethical considerations. Health Care Analysis, 1-20. doi: 10.1007/s10728-014-0287-2

Mahieu, L., \& Gastmans, C. (2012). Sexuality in institutionalized elderly persons: A systematic review of argument-based ethics literature. International Psychogeriatrics, 24(03), 346357.

Malmedal, W., Iversen, M. H., \& Kilvik, A. (2015). Sexual abuse of older nursing home residents: A literature review. Nursing Research and Practice, 2015, 1-7. doi:10.1155/2015/902515

Matthews, E. (2006). Dementia and the identity of the person. In J. C. Hughes, S. J. Louw \& S. R. Sabat (Eds.), Dementia: Mind, meaning and the person (pp. 163-177). Oxford, UK: Oxford University Press.

Merleau-Ponty, M. (1962). Phenomenology of perception (C. Smith, Trans.). London, UK: Routledge \& K. Paul.

Miles, S. H., \& Parker, K. (1999). Sexuality in the nursing home: Iatrogenic loneliness. Generations, 23(1), 36.

Miller, K. L., \& Kontos, P. (Forthcoming). The use of elder-clowning to foster relational citizenship in dementia care. In T. A. Andreassen, J. F. Gubrium \& P. K. Solvang (Eds.), Reimagining the human service relationship. New York, NY: Columbia University Press.

Millett, S. (2011). Self and embodiment: A bio-phenomenological approach to dementia. Dementia, 10(4), 509-522.

Mitchell, G. J., Dupuis, S. L., \& Kontos, P. (2013). Dementia discourse: From imposed suffering to knowing other-wise. Journal of Applied Hermeneutics, 1-19. http://jah.journalhosting.ucalgary.ca/jah/index.php/jah/article/viewFile/41/pdf

Ni Lochlainn, M., \& Kenny, R. A. Sexual activity and aging. Journal of the American Medical Directors Association, 14(8), 565-572. doi: 10.1016/j.jamda.2013.01.022

Nolan, M., Ryan, T., Enderby, P., \& Reid, D. (2002). Towards a more inclusive vision of dementia care practice and research. Dementia: The International Journal of Social Research and Practice, 1(2), 193-211.

Nussbaum, M. C. (1997). Capabilities and human rights. Fordham Law Reiew, 66, 273.

Obermueller, N. (2011). Assisted loving: Prostitutes and the elderly. Exberliner. Retrieved May 29, 2015, from http://www.exberliner.com/features/lifestyle/assisted-loving/

Parker, S. (2007). What barriers to sexual expression are experienced by older people in 24-hour care facilities? Reviews in Clinical Gerontology, 16(4), 275-279.

Phelan, S. (2010). Sexual strangers: Gays, lesbians, and dilemmas of citizenship. Philadelphia, PA: Temple University Press. 
Plummer, K. (2001). The square of intimate citizenship: Some preliminary proposals. Citizenship Studies, 5(3), 237-253. doi: 10.1080/13621020120085225

Plummer, K. (2003). Intimate citizenship: Private decisions and public dialogues. Seattle, WA: University of Washington Press.

Richardson, D. (1998). Sexuality and citizenship. Sociology, 32(1), 83-100. doi: 10.1177/0038038598032001006

Richardson, D. (2000a). Claiming citizenship? Sexuality, citizenship and lesbian/feminist theory. Sexualities, 3(2), 255-272. doi: 10.1177/136346000003002009

Richardson, D. (2000b). Constructing sexual citizenship: Theorizing sexual rights. Critical Social Policy, 20(1), 105-135. doi: 10.1177/026101830002000105

Richardson, D. (2015). Rethinking sexual citizenship. Sociology. doi: $10.1177 / 0038038515609024$

Roach, S. M. (2004). Sexual behaviour of nursing home residents: Staff perceptions and responses. Journal of Advanced Nursing, 48(4), 371-379. doi: 10.1111/j.13652648.2004.03206.x

Roelofs, T. S. M., Luijkx, K. G., \& Embregts, P. J. C. M. (2015). Intimacy and sexuality of nursing home residents with dementia: A systematic review. International Psychogeriatrics, 27(03), 367-384. doi: doi:10.1017/S1041610214002373

Rushbrooke, E., Murray, C. D., \& Townsend, S. (2014). What difficulties are experienced by caregivers in relation to the sexuality of people with intellectual disabilities? A qualitative meta-synthesis. Research in Developmental Disabilities, 35, 871-886.

Sabat, S. (2006). Mind, meaning, and personhood in dementia: The effects of positioning. In J. C. Hughes, S. J. Louw \& S. R. Sabat (Eds.), Dementia: Mind, meaning, and the person (pp. 287-302). Oxford, UK: Oxford University Press.

Sabat, S., \& Harré, R. (1992). The construction and deconstruction of self in alzheimer's disease. Ageing and Society, 12, 443-461.

Shakespeare, T. (2003). Disabled sexuality: Towards rights and recognition. Sexuality and Disability, 18(3), 159-166.

Shildrick, M. (2007). Contested pleasures: The sociopolitical economy of disability and sexuality. Sexuality Research \& Social Policy, 4(1), 53-66. doi: 10.1525/srsp.2007.4.1.53

Somers, M. R. (2008). Genealogies of citizenship: Knowledge, markets, and the right to have righta. Cambridge, UK: Cambridge University Press.

Somers, M. R., \& Roberts, C. N. J. (2008). Toward a new sociology of rights: A genealogy of "buried bodies" of citizenship and human rights. Annual Review of Law and Social Science, 4, 385-425. doi: 10.1146/annurev.lawsocsci.2.081805.105847

Syme, M. L. (2014). The evolving concept of older adult sexual behavior and its benefits. Generations, 38(1), 35-41.

Tepper, M. (2000). Sexuality and disability: The missing discourse of pleasure. Sexuality and Disability, 18(4), 283-290. doi: 10.1023/A:1005698311392

Tiefer, L. (2002). The emerging global discourse of sexual rights. Journal of Sex \& Marital Therapy, 28(5), 439-444.

Turner, B. S. (1993). Outline of a theory of human rights. Sociology, 27(3), 489-512. doi: $10.1177 / 0038038593027003009$

Turner, B. S. (2006). Vulnerability and human rights. University Park, PA: Pennsylvania University Press. 
Turner, B. S. (2009). A sociology of citizenship and human rights: Does social theory still exist. In R. Morgan \& B. S. Turner (Eds.), Interpreting human rights: Social science perspectives (pp. 177-199). New York, NY: Routledge.

Twigg, J. (2010). Clothing and dementia: A neglected dimension? Journal of Aging Studies, 24(4), 223-230.

Tzeng, Y. L., Lin, L. C., Shyr, Y. I., \& Wen, J. K. (2009). Sexual behaviour of institutionalised residents with dementia: A qualitative study. Journal of Clinical Nursing, 18(7), 9911001.

United Nations. (1948). Universal declaration of human rights.

Vancouver Coastal Health Authority. (2009). Supporting sexual health and intimacy in care facilities: Guidelines for supporting adults living in long-term care facilities and group homes in british columbia, canada. Vancover, BC.

Villar, F., Celdrán, M., Fabà, J., \& Serrat, R. (2014). Barriers to sexual expression in residential aged care facilities (racfs): Comparison of staff and residents' views. Journal of Advanced Nursing, 70(11), 2518-2527. doi: 10.1111/jan.12398

Ward, R., Pugh, S., \& Price, E. (2010). Don't look back? Improving health and social care service delivery for older lgb users. Equality and human rights commission, manchester, uk. Retrieved October 28, 2015, from http://www.equalityhumanrights.com/sites/default/files/documents/research/dont_look_b ack_improving health_and_social_care.pdf

Ward, R., Vass, A. A., Aggarwal, N., Garfield, C., \& Cybyk, B. (2005). A kiss is still a kiss? Dementia, 4(1), 49-72.

Weeks, J. (1998). The sexual citizen. Theory, Culture \& Society, 15(3), 35-52. doi: $10.1177 / 0263276498015003003$

Whitehouse, P. J. (2008). The myth of alzheimer's: What you aren't being told about today's most dreaded diagnosis. New York, NY: Macmillan.

Willis, P., Maegusuku-Hewett, T., Raithby, M., Miles, P., Nash, P., Baker, C., \& Evans, S. (2013). Provision of inclusive and anti-discriminatory services to older lesbian, gay, bisexualidentifying (lgb) people in residential care environments in wales. Wales, UK: Swansea University.

World Health Organization \& United Nations Office of the High Comissioner for Human Rights. (2008). Human rights, health and poverty reduction strategies. Health Human Rights Publications Series

Wronka, J. (2007). Human rights and social justice: Social action and service for the helping and health professions. Thousand Oaks, CA: SAGE Publications. 